\title{
Hyperthyroidism Secondary to Weight Loss Supplements
}

Kirsten Mitchell, Clinical Research Fellow

Claire McDougall, Consultant Endocrinologist

Hairmyres Hospital, East Kilbride, Scotland

\section{Case Report}

History

- 28 year old lady

- $\mathrm{PMH}$ - irritable bowel disease

- $\mathrm{DH}$ - combined oral contraceptive pill (10 years), no other regular prescribed medications.

- $\mathrm{SH}$ - non-smoker, occasional alcohol, lives with mother, works in customer services for a coffee supplier.

- Referred to endocrinology clinic in April 2015 after presenting to GP with swollen ankles and difficulty losing weight.

- Initial results suggested possible Cushing's disease with secondary hypothyroidism.

\section{Examination}

- Overweight - Weight $90.1 \mathrm{~kg}, \mathrm{BMI}-33$

- Clinically euthyroid

- No evidence of glucocorticoid excess

- No visual field defect

Initial Investigations

- $\mathrm{TSH}<0.05 \mathrm{mU} / \mathrm{L}$, free T4 2.0pmol/L (low) and free T3 3.2pmol/L (normal).

- Random cortisol $1266 \mathrm{nmol} / \mathrm{L}$
- Prolactin and growth hormone levels were normal

- FSH and LH fully suppressed due to COCP

- 24 hour urinary steroid profile was normal

- 8 am cortisol supressed to $42 \mathrm{nmol} / \mathrm{L}$ during overnight dexamethasone suppression test.

- MRI brain was normal

- Levothyroxine started at 50mcg daily.

Follow Up

- TFTs rechecked 8 weeks later (June 2015): TSH $<0.05 \mathrm{mU} / \mathrm{L}$, free T4 $12.2 \mathrm{pmol} / \mathrm{L}$.

- Levothyroxine was increased to $75 \mathrm{mcg}$ daily.

- October 2015: Patient now complaining of heat intolerance and hair loss. TFTs: $\mathrm{TSH}<0.05 \mathrm{mU} / \mathrm{L}$, free T4 $8.7 \mathrm{pmol} / \mathrm{L}$ (low) and free T3 raised at $44.0 \mathrm{pmol} / \mathrm{L}$ (high).

- Fictitious hyperthyroidism due to T3 ingestion was suspected.

- Detailed history revealed possible T3 ingestion in weight loss supplements purchased from a website (T5 fat burners).

Management

- Advised to discontinue all non-prescribed supplements.

- Repeat TFTs a few months later showed: TSH $1.70 \mathrm{mU} / \mathrm{L}$, free T4 $16.9 \mathrm{pmol} / \mathrm{L}$ and free T3 3.0pmol/L (all within normal range).

- Levothyroxine gradually reduced and stopped in November 2016.

- All repeat TFTs since then have been normal.

\section{Discussion}

Online weight loss supplements are largely unregulated by the Food and Drug Administration (FDA) or the Medicines and Healthcare products Regulatory Agency (MHRA) and could contain potentially harmful substances ${ }^{1}$.

There are several other case reports of dietary/weight loss supplements causing thyrotoxicosis.

Eliason et al (1994, US) ${ }^{2}$ report the case of a patient presenting with resting tachycardia, amenorrhoea and weight loss after taking a nutritional supplement containing thyroid tissue. Laboratory blood tests confirmed hyperthyroidism².

Ohye et al (2005, Japan) ${ }^{3}$ report a series of 12 patients who developed thyrotoxicosis after taking weight-loss supplements. Two of the investigators then took the supplements for 10 days and monitored their thyroid function. They found that free T3 levels began to rise after 2 hours of ingestion and reached a peak at 4-8 hours ${ }^{3}$.

Poon et al (2008, Hong Kong) ${ }^{4}$ report a series of 3 patients who developed factitious thyrotoxicosis after taking herbal supplements for weight reduction. The supplements were tested and found to contain animal thyroid tissue which was not declared on the ingredients list ${ }^{4}$.

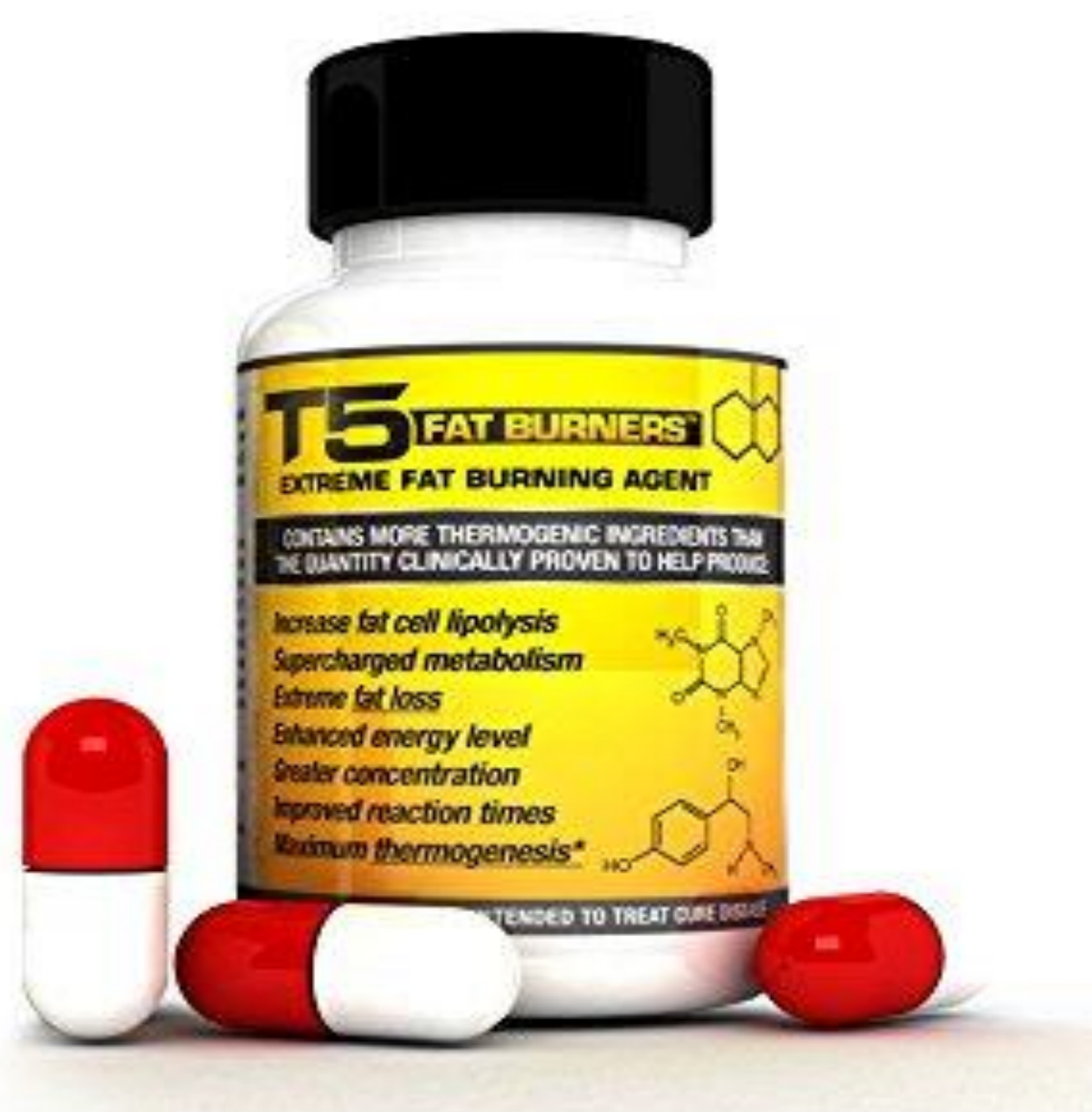

Graph: Patient's thyroid function tests (TFTs) over time.
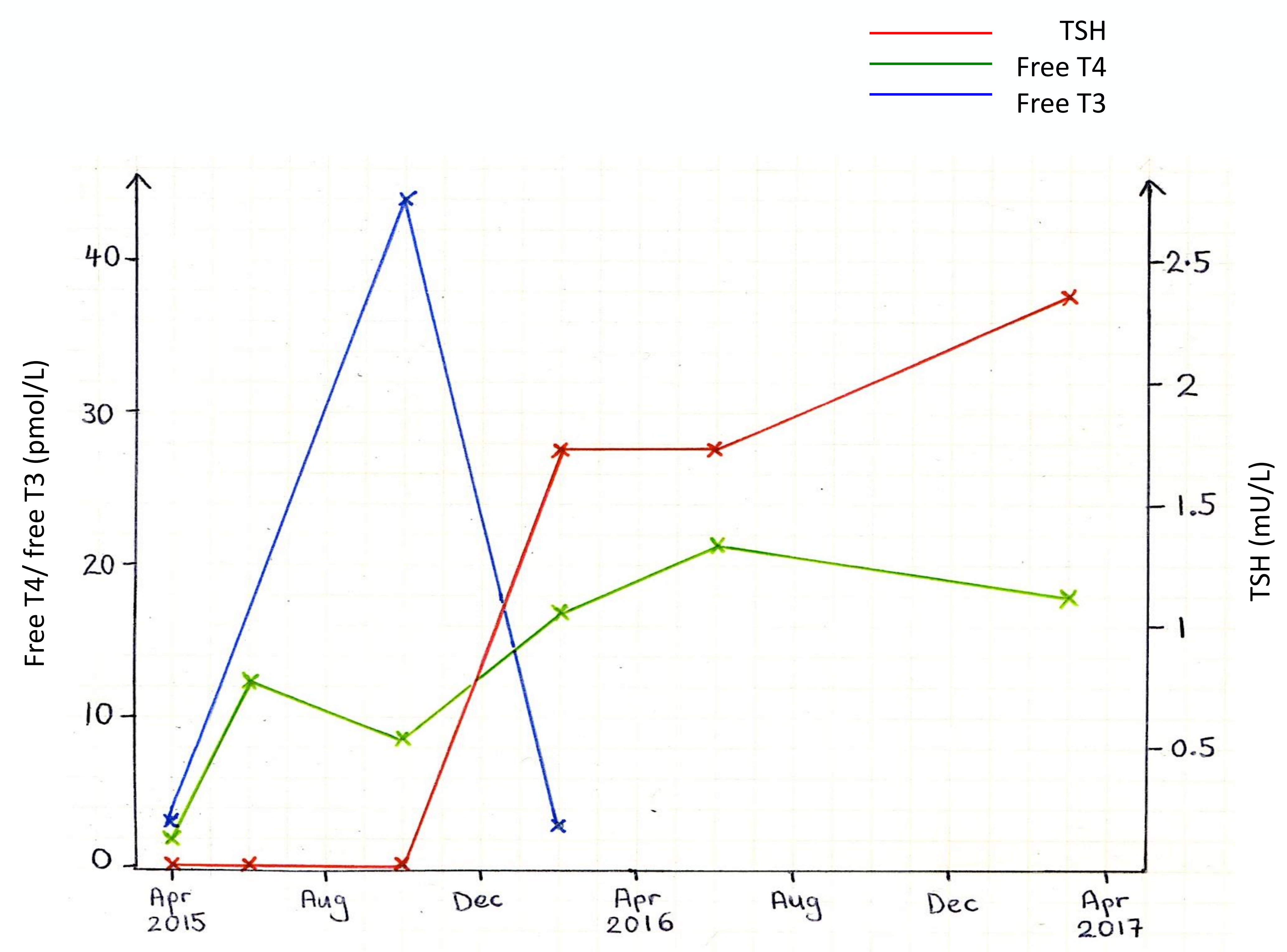

Key Messages

- Important to take a through drug history, including non-prescribed drugs/supplements bought online.

- Weight loss supplements may be a potential cause for factitious hyperthyroidism.

- Sporadic intake of exogenous thyroid hormones can mimic secondary hypothyroidism. 